\title{
A Tool for Evaluating Fault Detection and Diagnostic Methods for Fan Coil Units
}

\author{
Shokouh Pourarian ${ }^{1}$ \\ Amanda Pertzborn, $\mathrm{PhD}^{2}$,
}

\author{
Jin Wen, PhD ${ }^{1}$
}

Xiaohui Zhou, PhD $^{3}$
Daniel Veronica, PhD, $\mathrm{PE}^{2}$

Ran Liu, PhD ${ }^{3}$

\begin{abstract}
Dynamic simulation tools that could accurately simulate operational data for both the fault-free and faulty dynamic operation of heating, ventilation, and air conditioning (HVAC) systems and equipment are needed for developing and evaluating advanced control and automated fault detection and diagnosis strategies. Among various HVAC subsystems, fan coil units (FCUs) are relatively simple, inexpensive devices that are used extensively in commercial, institutional and multifamily residential buildings. However, very little bas been reported in the literature to improve FCU design and operation. There has also been a lack of dynamic simulation tool development focusing on FCUs. The work reported in this study aims at developing and validating a software tool to simulate operational data generated from FCUs that are operated dynamically under both faulty and fault-free conditions. A comprehensive and systematic validation process, using data collected from real FCUs in a laboratory building, is used to validate the tool under both faulty and fault-free operating conditions in different seasons. The validated tool not only is able to predict real-world FCU behaviors under different control strategies, but it is also able to predict symptoms associated with various faults, as well as the effects of those faults on system performance and occupant comfort.
\end{abstract}

\section{INTRODUCTION}

Over the past three decades, various computer software applications have been developed to simulate the dynamic interactions between the shell, internal loads, ambient conditions, and the heating, ventilating, and air conditioning (HVAC) systems of buildings. These software packages offering dynamic simulations of the actual physics of buildings are clearly distinct from software able only to simulate equilibrium quantities presumed to be static for significant periods of time, as in the hourly averaged simulations used to evaluate energy conservation options. By generating values that realistically simulate the transient physical quantities observed by real system instrumentation, dynamic simulation software serves as a platform — or, as called here, a tool—for research and development of advanced HVAC operation, controls, and automated fault detection and diagnosis (AFDD) strategies. Faulty operation of HVAC systems can be a result of component degradation, malfunction or improper control strategies, resulting in wasted energy and poor thermal comfort for building occupants. However, developing AFDD strategies using real building data requires implementing faults in these buildings, and thus is often impractical.

Dynamic simulation of HVAC systems can thus synthesize data representing the performance of real equipment under various control strategies. Further, by employing fault-inclusive models, dynamic simulations can synthesize data associated with various fault conditions and their effects on system performance and occupant comfort. These data and the tools are essential for advanced HVAC control and AFDD strategies development.

1: Department of Civil, Architectural and Environmental Engineering, Drexel University, Philadelphia, Pennsylvania. 2: Mechanical Systems and Controls Group of the Energy and Environment Division (EED) of the Engineering Laboratory (EL) at the National Institute of Standards and Technology (NIST). 3: lowa Energy Center, Ankeny, lowa. 
Extensive research has been conducted during the past decades in the area of AFDD to identify different technologies that are suitable for building HVAC systems (a good review is provided by Katipamula et al., 2001, 2005a, and 2005b, Yu et. al, 2014). Physical redundancy, heuristics or statistical bands, including the control chart approach, pattern recognition techniques, and innovation-based methods or hypothesis testing on physical models, are usually used to detect faults. Information flow charts, expert systems, semantic networks, artificial neural networks, and parameter estimation methods are commonly used to isolate faults. Heuristic rules and probabilistic approaches are used to evaluate faults. Based on the research, a series of AFDD products, including software and hardware, have been or are being developed. However, efficiently evaluating different AFDD technologies and products is not an easy task, and is well appreciated by professionals in this area.

To assist in the development and evaluation of chiller system AFDD methods, the American Society of Heating Refrigerating, and Air-conditioning Engineers (ASHRAE) sponsored research project 1043-RP "Fault Detection and Diagnostic Requirements and Evaluation Tools for Chillers" (Comstock and Braun, 1999a,b, Bendapudi and Braun, 2002). This project produced several experimental data sets of chiller operation under fault-free and faulty conditions (with different faults and four severity levels each), as well as a dynamic simulation model for centrifugal chillers. A similar project, ASHRAE 1312-RP “Tools for Evaluating Fault Detection and Diagnostic Methods for Air-Handling Units" (Li and Wen, 2010, Li et al, 2010, and Wen, 2010), produced extensive experimental data sets and a dynamic simulation testbed. The testbed was developed using the HVACSIM+ environment for use in an AFDD study of a single duct dual fan air handling unit (AHU). Several studies conducted by the National Institute of Standards and Technology (NIST) (Schein and Bushby, 2005 and Schein, 2006) generated simulation programs (using the HVACSIM+ environment) and laboratory and field data for variable air volume terminal system AFDD study.

However, for other typical secondary systems, such as a fan coil unit (FCU), there are very limited AFDD development and evaluation tools. There are also very limited experimental data sets for developing these tools. FCUs are relatively simple and inexpensive systems commonly used in commercial, institutional and multifamily residential buildings.

In the simulation-assisted and advanced HVAC control field, Kwak et al., 2015, Li et al., 2014, Colmenar-Santos et al., 2013, Privara et al., 2013 and Pang et al., 2012 provide good literature summaries indicating the significance of simulation in building energy management and performance optimization through predictive control. There are some publications that discuss fuzzy logic control of FCUs (Chu et al., 2005, Ghiaus, 2000) and evaluate a specific type of FCU performance (Ke et al., 2007), but there has been no prior publication that discusses the dynamic simulation of FCUs, especially when faults exist.

A FCU consists of a fan and at least one air-water heat exchanger coil for heating or cooling airflow. To condition a space, hot or cold water is circulated through the FCU coil to add or remove heat from the airstream discharged to the space by the fan. The amount of heating or cooling is regulated primarily by control of the water flow and secondarily by control of the speed of the fan. Unit configurations include horizontal (ceiling mounted) or vertical (floor mounted). There are also two distinct configurations with regard to the water side. Two-pipe FCUs have one supply pipe, providing hot or cold water to the coil depending on the season, and one return pipe. Four-pipe FCUs have two supply pipes and two return pipes. This allows hot and cold water to enter the unit at any given time. Since it is often necessary to heat and cool different areas of a building at the same time, due to differences in internal heat loss and heat gain, the four-pipe fan coil unit is the most commonly used (ASHRAE Handbook, 2008).

The work described here models a vertical four-pipe hydronic FCU as a component within the HVACSIM+ dynamic simulation software package. The FCU model is capable of generating operational data of a four-pipe FCU under both fault-free and faulty conditions. In order to validate the FCU model, a system model that simulates a FCU interacting with a zone is also developed in the HVACSIM+ environment using an existing zone model and compared with experimental results. In this paper, the test facility and experiments used to validate the developed model are introduced first. Next, the HVACSIM+ environment, the model (including both fault-exclusive and fault-inclusive models) development and validation process, and results are described.

\section{TEST FACILITY AND EXPERIMENTAL SET UP}

For the purpose of validation of fault-exclusive and fault-inclusive models, extensive experiments were conducted at 
the Iowa Energy Center Energy Resource Station (ERS) on FCUs in three different seasons to generate operational data under a wide variety of fault-free and faulty operational conditions. A detailed description about the ERS can be found in earlier studies (Norford et al. 2000, Castro et al. 2003, Li et al. 2010).

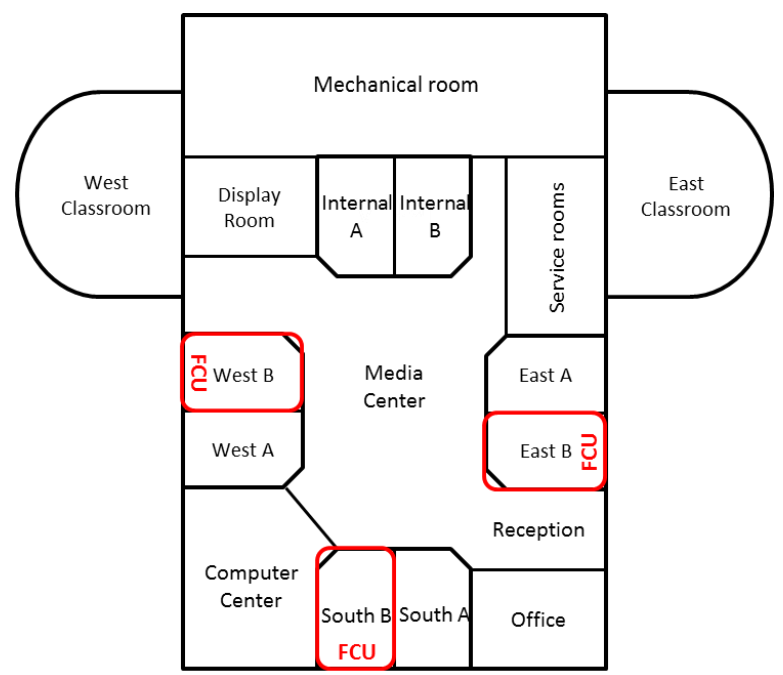

Figure 1 The schematic of Energy Resource Station building zones equipped with FCU (Price and Smith 2003)

Three ERS test rooms with exterior exposures, east-B, south-B and west-B (Figure 1), are equipped with FCUs of a common configuration. Each of these three rooms is equipped with a vertical four-pipe hydronic FCU with three 3-speed fans (high, medium, and low speeds). The amount of outdoor air ventilation supplied to the zone is controlled by a motorized damper at the back of the unit. Figure 2 shows a schematic of the FCU at ERS.

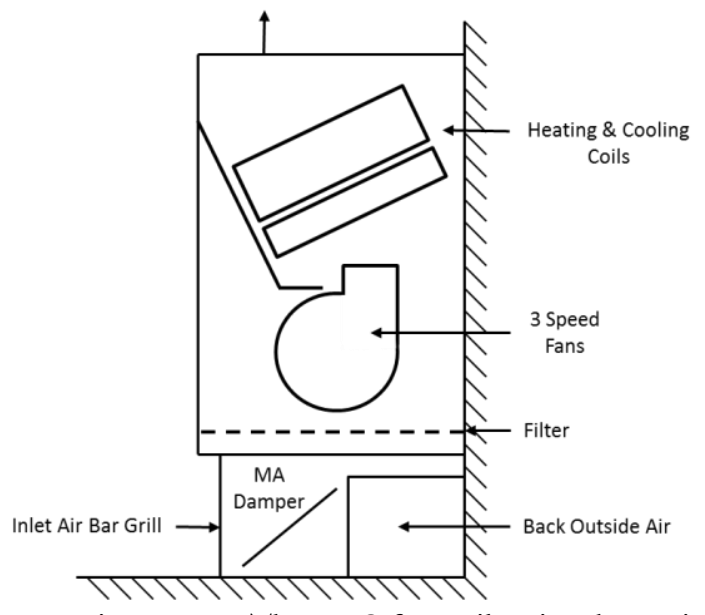

Figure 2 The ERS fan coil unit schematic

The control mode of the FCU can be either "Unoccupied" or "Occupied." In the "Unoccupied" mode, the fan is off, the mixed air damper and heating and cooling coil valves are fully closed, and the test room temperature floats. In the "Occupied" mode, the FCU is controlled to maintain the test room thermostat heating and cooling setpoints, with the 3speed fan in one of three modes of operation: "Automatic On/Off" with variable fan speed control, "Always On" at a predetermined speed, and "Cycle On/Off" at a predetermined speed.

In this study, when the FCU is in "Occupied" mode, the mixed air damper position is fixed at $0 \%$ open in summer 
and $30 \%$ open in fall and winter. The fan speed is set to be in the "Always ON" mode with speed set to high and the mixed air temperature is not controlled. The FCU controller compares the room temperature to a cooling setpoint $\left(22.2^{\circ} \mathrm{C}\right.$ in fall and winter, $23.3{ }^{\circ} \mathrm{C}$ in summer) and a heating setpoint $\left(20{ }^{\circ} \mathrm{C}\right.$ in fall and winter, $21.1{ }^{\circ} \mathrm{C}$ in summer). If the actual room temperature is greater than (cooling setpoint $-0.56^{\circ} \mathrm{C}$ ), the FCU is in "cooling" mode, and if it is less than (heating setpoint $\left.+0.56{ }^{\circ} \mathrm{C}\right)$, the FCU is in "heating" mode. A dedicated PID loop is used for each mode to control the cooling or heating valve position to maintain the setpoint.

During the experiments, control signals including cooling and heating coil valve positions and outdoor air damper position, as well as measurements such as room air temperature, discharge and mixed air temperatures and hot water flow rate are recorded. To generate FCU data under normal conditions, all rooms are operated initially without imposed faults (fault-free tests). To generate data under faulty conditions, the east-B and west-B test rooms are operated with deliberately imposed faults while the south room is operated normally (without any imposed fault).

\section{FAULT-EXCLUSIVE MODEL AND VALIDATION PROCEDURE}

This section first introduces the HVACSIM+ environment then presents the structure of the fault-exclusive model that simulates an FCU interacting with a zone in HVACSIM+ and the validation procedure of this fault-exclusive model. The FCU model developed here is validated by comparing the data from simulated operation under faulty and fault-free conditions with the corresponding experimental data from ERS.

\section{HVACSIM+}

The HVACSIM+ software (Park et al, 1985), developed by the U.S. National Institute of Standards and Technology (NIST), employs a unique hierarchical computation approach for modeling a building system. Individual simulation elements (called "units", such as mixing boxes, fans, cooling/heating coils, ducts, controllers, and actuators) are first grouped by the user into "blocks" (subsystems, such as the air handling unit airflow network) for simultaneous solution. Blocks are then similarly grouped into "superblocks" (such as the entire airflow network of a HVAC system) for simultaneous solution. Each superblock is a numerically independent subsystem of the overall simulation. For example, an airflow network superblock can be simulated independently from a water flow network at each time step. Its time evolution and internal solutions are propagated independently of other superblocks. The time step in a superblock is a variable that is automatically and continuously adjusted by a solver subroutine to maintain numerical stability. The typical time step for dynamic HVAC system simulation is 2 to $5 \mathrm{~s}$.

Each individual unit is an instance of a specifically serialized piece of equipment or device as described above. Each such piece of equipment or device is modeled in a "TYPE" (written all caps to distinguish it from the common use of the word), which is provided by the HVACSIM+ environment as part of a component model library. For example, HVACSIM+ provides TYPE 305, representing the flow state of the fan and TYPE 403, representing the thermal state of the room. To develop a simulation model in HVACSIM+, one needs to 1) choose the correct TYPEs for each unit and define their parameters, and 2) connect units into blocks and superblocks by defining inputs and outputs. For example, by defining the inputs of Unit 2 as the outputs of Unit 1, HVACSIM+ would connect these two units together. Step 3) is to define simulation parameters, such as duration of the simulation and whether to use a fixed time step or flexible time step. This hierarchical approach makes complex simulations solvable. HVACSIM + has been experimentally validated and improved (Dexter et al., 1987) for many types of HVAC systems such as single duct variable air volume air handling unit (Li et al. 2010), and has proven useful for fault-inclusive modeling (Bushby et al. 2001, Dexter, 1995, and Peitsman et al. 1997).

In order to allow a user to simulate this secondary system under both fault-free and faulty operating conditions, we have provided a TYPE representing a four-pipe FCU in the HVACSIM+ library of components.

\section{Overall Model Structure}

Modeling a HVAC device in HVACSIM+ typically requires the user to: 1) divide the device into smaller units, each of which can be represented by a TYPE provided in the HVACSIM+ library of components; 2) group units into blocks; 3) 
group blocks into superblocks. Previous studies (Norford et al. 2000, Castro et al. 2003, Li et al. 2010) provide examples of this process.

Following the experience obtained in these earlier studies five superblocks (each including one block) are designed for FCU modeling: (1) control logic (SB1), (2) actuators (SB2), (3) fluid (i.e., mass flow and pressure, SB3), (4) thermal (temperature and humidity, SB4), and 5) sensors (SB5). Figure 3 illustrates this HVACSIM+ structure for the FCU model. New TYPES, namely TYPE 479, 307 and 314, are developed in this study representing, the control logic, mass flows, and thermal states of a FCU, respectively. Details about these FCU specific models are provided in the following section.

As illustrated in Figure 3, there are five superblocks, represented by SB1 to SB5. Each rectangular box represents a unit (described by its title). The TYPE number used to model each unit is also provided, such as T479 (TYPE 479) for fan coil unit supply air temperature control. $\mathrm{C}$ represents a control signal, $\mathrm{N}$ represents rotational speed and $\mathrm{T}$ represents temperature. For example, it can be seen that the mixed air and room air temperature signals $\left(\mathrm{C}_{11}\right.$ and $\left.\mathrm{C}_{10}\right)$, sent from the sensors superblock (SB5) to the controls superblock (SB1) result in positioning of the heating and cooling coil valves and the mixed air damper (SB2). Simultaneous solution of mass-pressure equations occurs in the fluid superblock (SB3), while energy balance equations are solved simultaneously in the thermal superblock (SB4).

The simulation of this FCU+zone model is influenced by the following parameters and conditions: 1) device performance parameters (details are further discussed in the following section), and 2) boundary conditions including zone interior loads, outdoor air temperature and humidity, neighboring zone and plenum temperatures, and inlet cooling and heating water temperatures and pressures. The types of controllable internal loads in each test room are: lighting loads, office equipment loads, and loads generated by the baseboard heaters to represent sensible occupant loads. The values of these boundary conditions are determined from the test facility measurements. The simulations run for each test day (86400 $\mathrm{s})$ with a minimum time step of $2 \mathrm{~s}$ and a maximum time step of $10 \mathrm{~s}$ to confine the solver as it automatically adjusts the time step and avoids inaccuracy and instability of the simulation.

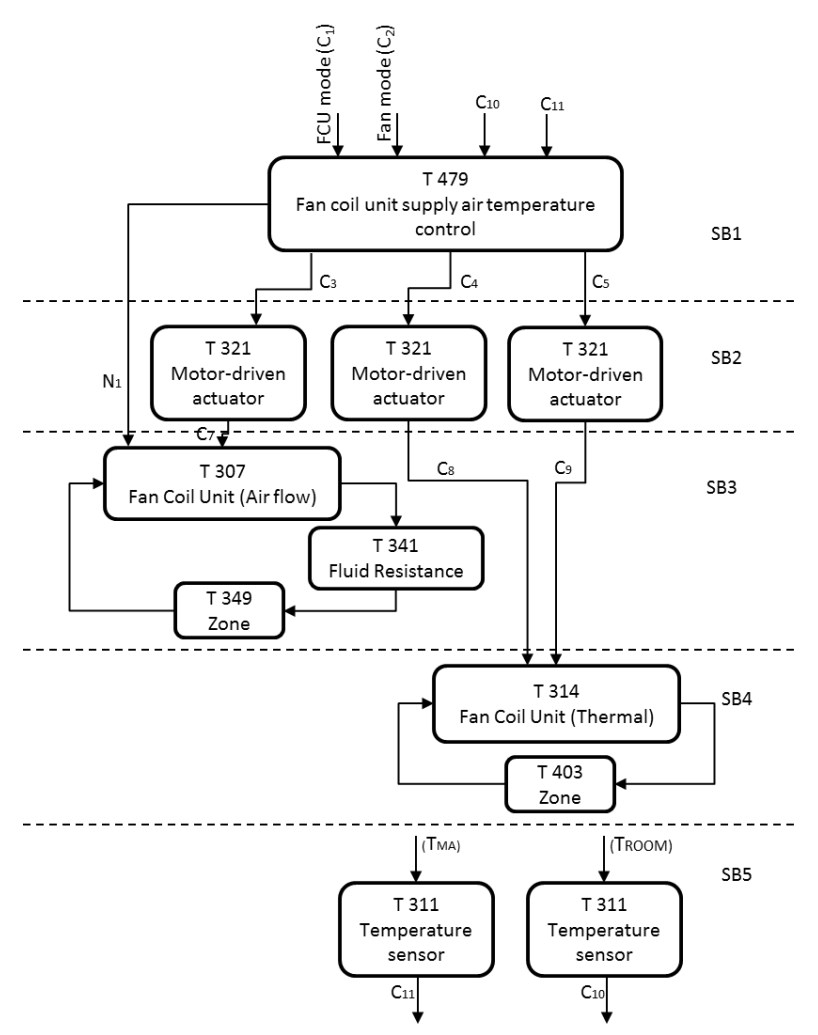

Figure 3 Fan coil unit model structure in HVACSIM+ 


\section{Validation Procedure}

The dynamic behavior of the model is validated by comparing simulation results with experimental data at two levels: the component level and the system level. When validating a component level model, the focus is on the parameters of the model. During model development, parameters of a component are obtained from manufacturer data or component tests (if no suitable manufacturer data are available). For those parameters obtained from manufacturer data, component level validation is still conducted to ensure realistic model behavior. In this study, the following component tests are available for component level validation: mixed air damper test, fan test, and heating and cooling coil valves tests. The process and validation of modeling the relationships among mixed air damper pressure resistance, pressure drop, airflow rate, and damper openings are summarized by $\mathrm{Li}$ et al., 2010. Using the fan component test to obtain a model that represents the relationships among fan static pressure rise, airflow rate, fan diameter and rotational speed is described by $\mathrm{Li}$ and Wen, 2010. In the following section, the validation of the developed cooling and heating coil valve models using component tests is discussed as an example of component level validation.

Dynamic simulation using the FCU as part of a system model requires an interacting zone model, including systemic interactions with the building's surroundings. The details of the zone model, TYPE 403 in the HVACSIM+ library of components, are provided in $\mathrm{Li}$ and Wen 2010. Zone parameters from the ASHRAE 1312 research project (Wen and Li, 2011) are used in this study since they are validated using data from the same facility. Variables examined for system level validation included cooling and heating coil valve positions, room air temperature, mixed air damper position and hot water flow rate. Although discharge and mixed air temperatures are measured in the test facility, they were not used for validation due to large experimental uncertainty caused by uneven flow profiles around sensors.

\section{Example of Component Model Validation: Cooling and Heating Coil Valve Model}

HVACSIM+ provides a two-port valve model, illustrated in Figure 4, which uses functions rlinport and reqpport. This valve model can simulate either linear or nonlinear (equal percentage) behavior. When valve position varies, valve resistance changes and results in the change of water flow rate through the coil. Two resistances are used in the two-port valve model: coil flow resistance (Rcoil) and valve resistance (Rvalve).

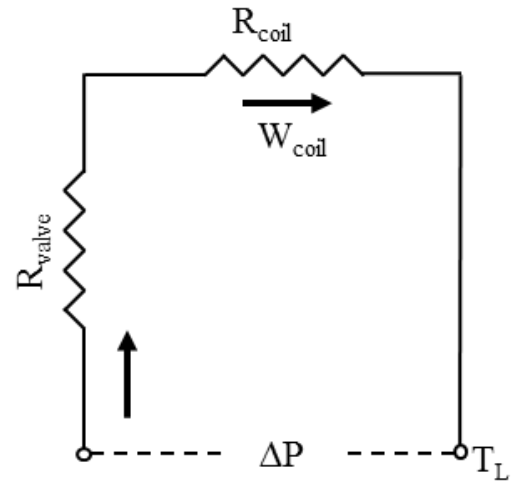

Figure 4 Diagram of a two-port valve model

All control valves have an inherent flow characteristic that defines the relationship between valve opening and flowrate under constant pressure conditions. In order to model the heating and cooling coil valve properly, an experiment was conducted in which valve position was systematically varied from $0 \%$ to $100 \%$ open and the flow rate through the valve was measured while pressure drop across the cooling and heating coils was held constant. In order to provide plenty sufficient number of data points, the heating and cooling valve testing experiment was repeated three times, varying the fan speed from low to high (experimental data set 1-3 in Figure 5, 6). The experimental data indicated that the two valve gains (defined as the change in flow per unit \% change in the valve opening) have neither linear characteristics nor equal 
percentage characteristics (Figure 5). Both heating and cooling valve characteristics are divided into three regions: cut off region $\left(0<\mathrm{x}<\mathrm{x}_{1}\right)$; linear region $\left(\mathrm{x}_{1}<\mathrm{x}<\mathrm{x}_{\mathrm{h}}\right)$; and high-end region $\left(\mathrm{x}_{\mathrm{h}}<\mathrm{x}<1\right)$, which are typically observed and modeled in larger valves ( $\mathrm{Li}$ and Wen, 2010). For the cooling coil valve these regions are, respectively, ( $0 \%$ to $10 \%$ open), (10\% to $80 \%$ open), and ( $80 \%$ to $100 \%$ open). For the heating coil valve these regions are, respectively, (0\% to $10 \%$ open), (10 $\%$ to $70 \%$ open) and (70 \% to $100 \%$ open).

Because the existing function, rlinport, could not model this kind of segmented characteristic, it is modified as a new valve model function, rlinport3. In rlinport3, two resistances, Rcoil and Rvalve, are calculated based on the valve position and valve characteristics. The following equation is used to calculate valve resistance (Norford and Haves, 1997):

$R_{\text {valve }}=1296 K_{v}^{-2} f^{-2}$ (SI unit) $\quad$ or $\quad R_{\text {valve }}=66.94 K_{v}^{-2} f^{-2}$ (IP units)

where $K_{v}$ is valve capacity ( $\mathrm{m}^{3} / \mathrm{h}$ or GPM) and $f$ is fractional flow (\%). $f$ is a function of valve position $x$ and is calculated using the following equation:

$f=a x+b$.

$a$ and $b$ are defined as follows:

For cut-off region $\left(0<x<x_{l}\right)$ :

$a=0$ and $b=C_{L}$.

For linear region $\left(x_{l}<x<x_{b}\right)$ :

$a=\frac{C_{H}-C_{L}}{x_{h}-x_{l}}$ and $b=\frac{x_{h} C_{L}-x_{l} C_{H}}{x_{h}-x_{l}}$.

For high end region $\left(x_{b}<x<1\right)$ :

$a=\frac{1-C_{H}}{1-x_{h}}$ and $b=\frac{C_{H}-x_{h}}{1-x_{h}}$.

$C_{L}$ and $C_{H}$ are parameters representing the fractional flow rate corresponding to valve positions at $x_{l}$ and $x_{b}$, respectively, and are obtained from experimental data. Figures 5 and 6 show the measured flow rate $(\mathrm{kg} / \mathrm{s})$ as a function of valve opening $(0=$ fully closed, $1=$ fully open $)$ for the cooling and heating valves, respectively. From Figure 5 , at $x_{l}=0.10$, the fractional flow rate is $C_{L}=0.0001(0.000037 \mathrm{~kg} / \mathrm{s})$ and at $x_{b}=0.8$, the fractional flow rate is $C_{H}=0.983(0.364 \mathrm{~kg} / \mathrm{s})$. A similar analysis of Figure 6 yields values of $C_{L}=0.00019$ and $C_{H}=0.970$ for the heating valve.

Water flow rate through the coil is calculated by:

$W=\sqrt{\frac{\Delta P}{R}}$

where $W$ is the coil water flow rate $(\mathrm{kg} / \mathrm{s}$ or GPM) and $\Delta P$ is the pressure drop across the coil and valve ( $\mathrm{kPa}$ or in. w.c). $R$ is the total flow resistance $(0.001 \mathrm{~kg} . \mathrm{m}$ or $0.001 \mathrm{lbm} . \mathrm{ft})$ as calculated by:

$R=R_{\text {coil }}+R_{\text {valve }}$

Equations (1) to (7) are combined to obtain the following model equation: 
$\frac{1}{W^{2}}=\frac{1296}{\Delta P K_{v}{ }^{2}}(a x+b)^{-2}+\frac{R_{\text {coil }}}{\Delta P}(S I$ unit $) \quad$ or $\quad \frac{1}{W^{2}}=\frac{66.94}{\Delta P K_{v}{ }^{2}}(a x+b)^{-2}+\frac{R_{\text {coil }}}{\Delta P}($ IP unit $)$

This equation can be rewritten in the linear form:

$y=\theta_{1} \emptyset_{1}+\theta_{2} \emptyset_{2}$,

where $\mathrm{y}=\frac{1}{W^{2}}, \emptyset_{1}=(a x+b)^{-2}, \emptyset_{2}=1, \theta_{1}=\frac{1296}{\Delta P K_{v}{ }^{2}}$ and $\theta_{2}=\frac{R_{\text {coil }}}{\Delta P}$. This equation contains two unknown parameters, Rcoil and $K_{\nu}$. These unknowns can be calculated by transforming the experimental data shown in Figures 5 and 6 to $1 / W^{2}$ as a function of valve position $x$ and then applying the least squares method using 3 experimental data sets to Eq. 9. Table 1 summarizes the resulting parameters for the cooling and heating coil valves. Figures 5 and 6 show the comparison between the simulated cooling and heating coil water flow rate and the corresponding experimentally measured values. The predicted flow rate is a reasonable match to the experimental flow rate $\left(R^{2}=0.56\right.$ for cooling coil valve and $R^{2}=0.64$ for heating coil valve).

Table 1. Cooling and heating coil valves parameters estimated from experimental data

\begin{tabular}{|l|l|l|}
\hline Parameters & Explanation & Value \\
\hline $\mathrm{R}_{\text {cooling coil }}$ & Cooling coil water flow resistance, $0.001 \mathrm{~kg}-\mathrm{m}$ & 90.18 \\
\hline $\mathrm{K}_{\text {V-cooling coil }}$ & Cooling coil valve capacity, $\mathrm{m}^{3} / \mathrm{h}$ & 0.93 \\
\hline $\mathrm{C}_{\mathrm{L}-\text {-cooling coil }}$ & Cooling coil valve leakage (fractional flow), $\%$ & 0.0001 \\
\hline $\mathrm{C}_{\mathrm{H}-\text { cooling coil }}$ & Cooling coil high-end fractional flow, $\%$ & 0.9834 \\
\hline $\mathrm{R}_{\text {heating coil }}$ & Heating coil water flow resistance, $0.001 \mathrm{~kg}-\mathrm{m}$ & 9584.4 \\
\hline $\mathrm{K}_{\text {V-heating coil }}$ & Heating coil valve capacity, $\mathrm{m}^{3} / \mathrm{h}$ & 0.45 \\
\hline $\mathrm{C}_{\mathrm{L} \text {-heating coil }}$ & Heating coil valve leakage (fractional flow), $\%$ & 0.0002 \\
\hline $\mathrm{C}_{\text {H-heating coil }}$ & Heating coil high-end fractional flow, $\%$ & 0.9703 \\
\hline
\end{tabular}




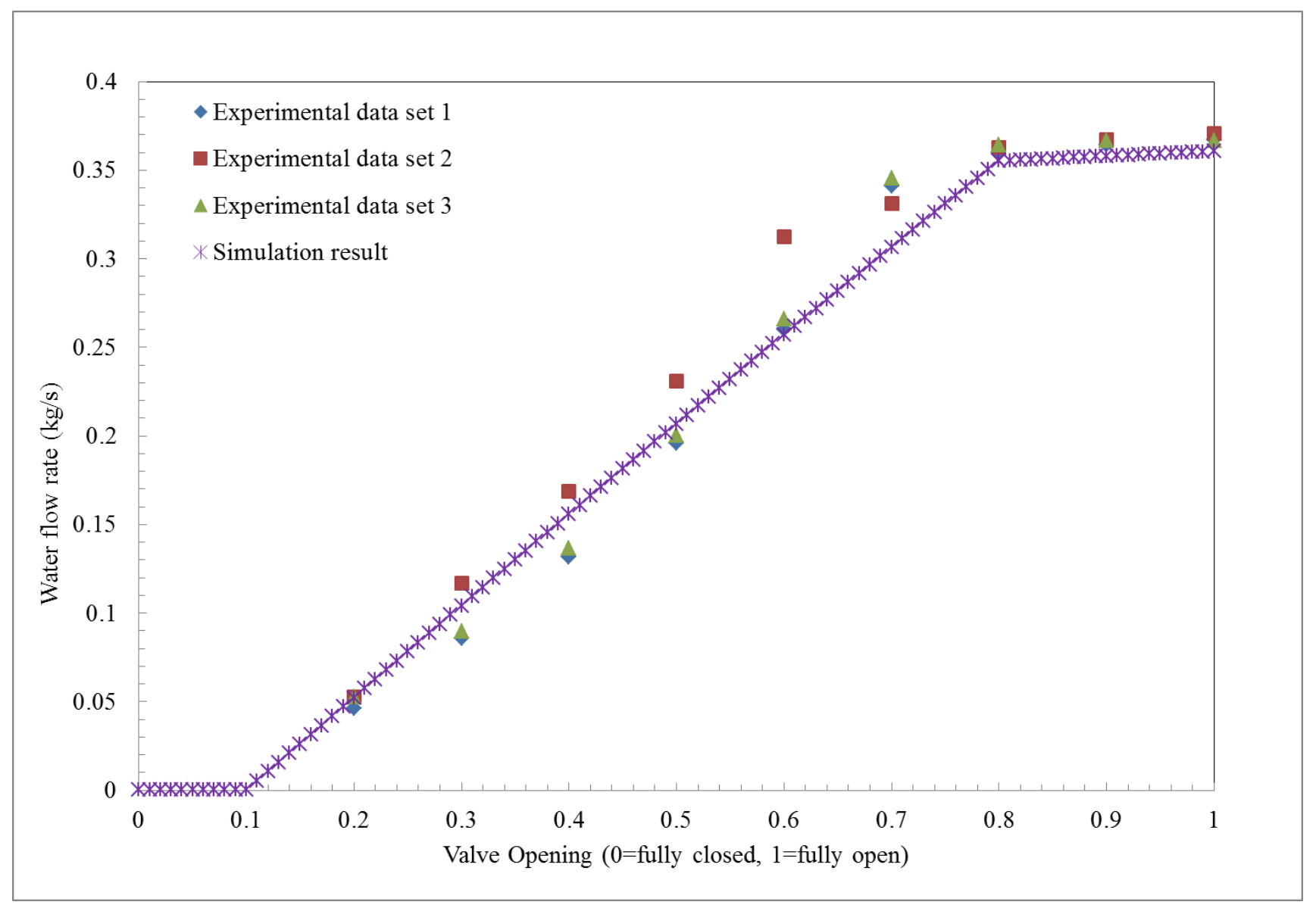

Figure 5 Experimental and simulated water flow rates vs. valve opening for cooling coil 


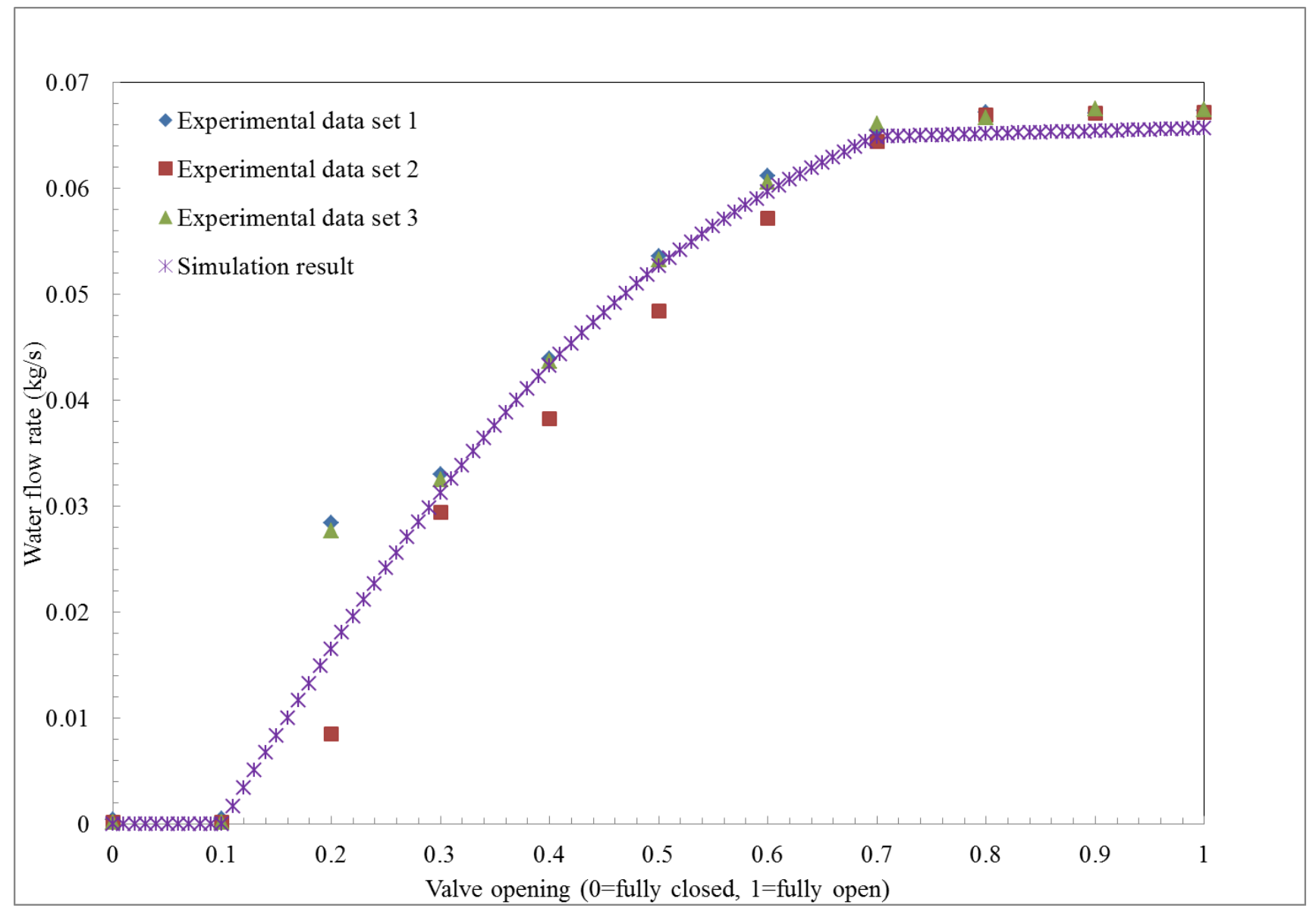

Figure 6 Experimental and simulated water flow rates vs. valve opening for heating coil

\section{FAULT-INCLUSIVE MODEL DEVELOPMENT AND VALIDATION PROCEDURE}

Faults can be modeled in two ways (Haves, 1997): 1) by changing existing parameter values in a fault-exclusive model, such as reducing the UA value (heat conductance coefficient) to model a fouled coil in a simple coil model, and 2) by extending the structure of a fault-exclusive model to treat faults explicitly, such as modeling a coil fouling fault by adding a new parameter that specifies the thermal resistance of the deposit in a detailed coil model. In this study, faults were modeled in both ways using the methods described in the ASHRAE 1312 project (Wen and Li, 2011). A fault flag arrangement was employed to allow the user to select a fault type and severity. Given that the simulation system model was validated under fault-free conditions, the only further validations required to ensure realistic representation of faults were those on the fault models. The category of faults which may occur in FCUs, and the devices affected by these faults, are listed in Table 2. Varying severity, which relates proportionally to the fault symptoms observable in the data, can be simulated by the fault-inclusive FCU model.

A naturally occurring fault could impact the system in a fairly complicated manner. Since the application of a faultinclusive model is for AFDD strategy development, the focus of validating a fault-inclusive model is on ensuring that the model produces correct fault symptoms rather than regenerating the exact system dynamics.

During the validation process, fault-inclusive simulation results were first compared to fault-exclusive simulation results (simulated under the same weather and internal load boundary conditions) in order to identify the simulated fault symptoms. Then, experimental data obtained with artificially embedded faults were compared with those under fault-free 
conditions. Ideally, two identical systems, one implemented with a fault and the other without a fault, would be operated side by side. Fault symptoms could be easily identified by comparing measurements from these two systems. However, such operation is not possible in the test facility due to the lack of an FCU system in all test rooms. Thus, a normal test day with close or more severe weather condition (that is, a condition that will cause system variables to change similarly as the tested fault) was selected as a reference day to identify experimental fault symptoms. Simulated fault symptoms were then compared with experimental fault symptoms to validate the fault-inclusive models.

Table 2. FCU Fault Summary

\begin{tabular}{|c|c|c|c|c|c|c|}
\hline Category & Device & Fault Name & Fault Type & $\begin{array}{c}\text { Summer Test } \\
\text { Days }\end{array}$ & $\begin{array}{l}\text { Fall Test } \\
\text { Days }\end{array}$ & $\begin{array}{c}\text { Winter Test } \\
\text { days }\end{array}$ \\
\hline \multirow{9}{*}{ Equipment } & \multirow{2}{*}{ Fan } & Failure & A Abrupt & & $\overline{11}$ & \\
\hline & & Outlet Blockage & Abrupt & & 1 & \\
\hline & \multirow{2}{*}{ Heating Coil } & Fouling-Air side & Degradation & & & 2 \\
\hline & & Fouling-Water side & Degradation & & & 1 \\
\hline & \multirow{2}{*}{ Cooling Coil } & Fouling-Air side & Degradation & 2 & & \\
\hline & & Fouling-Water side & Degradation & 2 & & \\
\hline & \multirow[t]{2}{*}{ Filter } & Filter Restriction & Degradation & 1 & & 1 \\
\hline & & Restricted Airflow & Opening Blockage & & 1 & 1 \\
\hline & Economizer & $\begin{array}{c}\text { Leaking OA/RA } \\
\text { DMPR }\end{array}$ & Degradation & & 1 & 1 \\
\hline \multirow{2}{*}{ Sensor } & Room Temp & Offset & Degradation & 2 & & 2 \\
\hline & MA Temp & Offset & Degradation & & 2 & 2 \\
\hline \multirow{11}{*}{ Controlled Device } & \multirow{4}{*}{ Heating Valve } & \multirow{3}{*}{ Stuck } & Full Open & & & 1 \\
\hline & & & Full Closed & & & 1 \\
\hline & & & Partial Open & & & 1 \\
\hline & & Leaking & Degradation & & & 1 \\
\hline & \multirow{4}{*}{ Cooling Valve } & \multirow{3}{*}{ Stuck } & Full Open & 1 & & \\
\hline & & & Full Closed & 1 & & \\
\hline & & & Partial Open & 1 & & \\
\hline & & Leaking & Degradation & 1 & & \\
\hline & \multirow{3}{*}{ Mixed air Damper } & \multirow{3}{*}{ Stuck } & Full Open & 1 & 1 & \\
\hline & & & Full Closed & & 1 & \\
\hline & & & Partial Open & 1 & 1 & 1 \\
\hline \multirow{5}{*}{ Control } & $\begin{array}{l}\text { FCU Cycle I } \\
\text { Control }\end{array}$ & Unstable Control & Degradation & 1 & 1 & \\
\hline & $\begin{array}{l}\text { FCU Cycle II } \\
\text { Control }\end{array}$ & Unstable Control & Degradation & 1 & 1 & \\
\hline & $\begin{array}{l}\text { FCU Cycle III } \\
\text { Control }\end{array}$ & Unstable Control & Degradation & & 1 & 1 \\
\hline & Heating Control & Control Misdirection & Implementation & & 1 & 1 \\
\hline & Cooling Control & Control Misdirection & Implementation & 1 & 1 & \\
\hline
\end{tabular}

\section{RESULTS AND DISCUSSION}

Experimental data from 8 fault-free days ( 3 days in summer, 3 days in winter, and 2 days in fall) are used to validate the fault-exclusive model. All experimental data summarized in Table 2 are used to validate the fault-inclusive model. Overall, the developed FCU model successfully reproduces the dynamics of a FCU, as well as the fault symptoms of all modeled FCU faults. The following figures show only a few test days in order to illustrate validation cases of the FCU model under fault-free conditions and typical validation cases under faulty conditions. 
Figure 7 shows the simulation and experimental results in the east and south-facing rooms on a winter test day (01.08.2012) under fault-free conditions. The red line represents experimental data and the navy blue dashed line represents simulation data. Again, during the validation of the fault-exclusive model, heating and cooling coil valve positions and hot water flow rate as well as room air temperature measurements are compared with the corresponding simulated data. During winter operation the mixed air damper position is set to $30 \%$ open, so the mixed air damper position is not presented here.

Examining Figure 7, for both rooms there are certain discrepancies between the simulated and experimental cooling and heating coil valve positions, which occur for several reasons. First, the component tests for valve model validation were only performed in the south facing room. Hence, the simulation results are closer to the experimental data in the south facing room system. Although the ERS FCUs in the exterior rooms are identical, there are unavoidable differences that may not be captured in this work. Second, the zone simulation model is more sensitive to changes in internal load and ambient air fluctuations than the actual zone. For example, at approximately the 780th minute, the heating coil valve closes $(0 \%$ open) in the test system for both rooms. At the corresponding time, the room air temperature plot shows a sharper and faster increase in room temperature in the simulation than in the real room. The simulated room air temperature is representative of well mixed air within the room, but in reality the actual room temperature sensor may reflect a local temperature that is not necessarily reflective of the bulk room temperature. The dynamics of the modeled FCU display some deviation from the real FCU due in part to unavoidable simplifications to the zone model that were necessary to keep the zone model tractable. Since the focus of this study is on FCU model development, future study is needed to further improve the zone model.

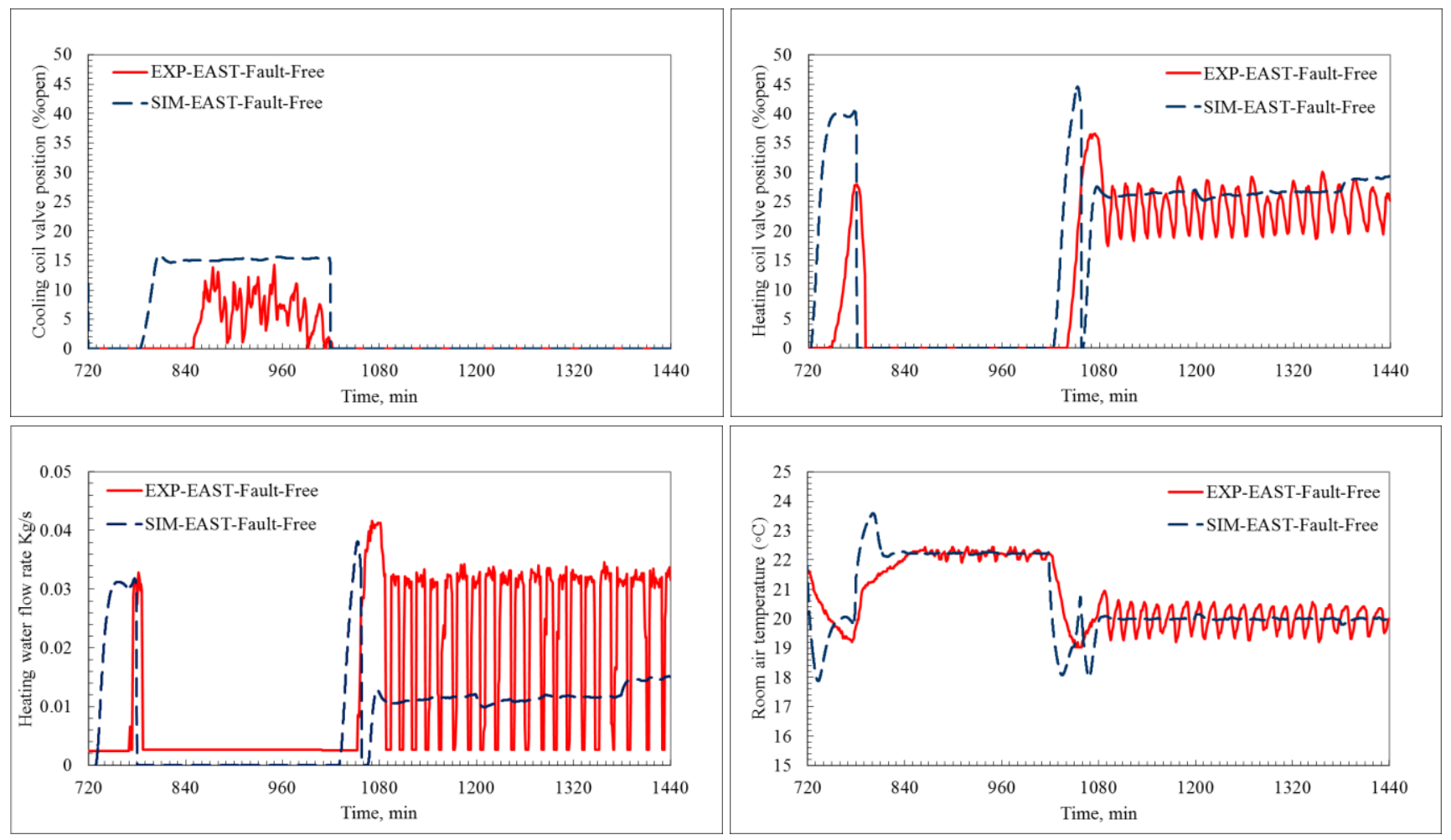

(a) East-facing room validation results 


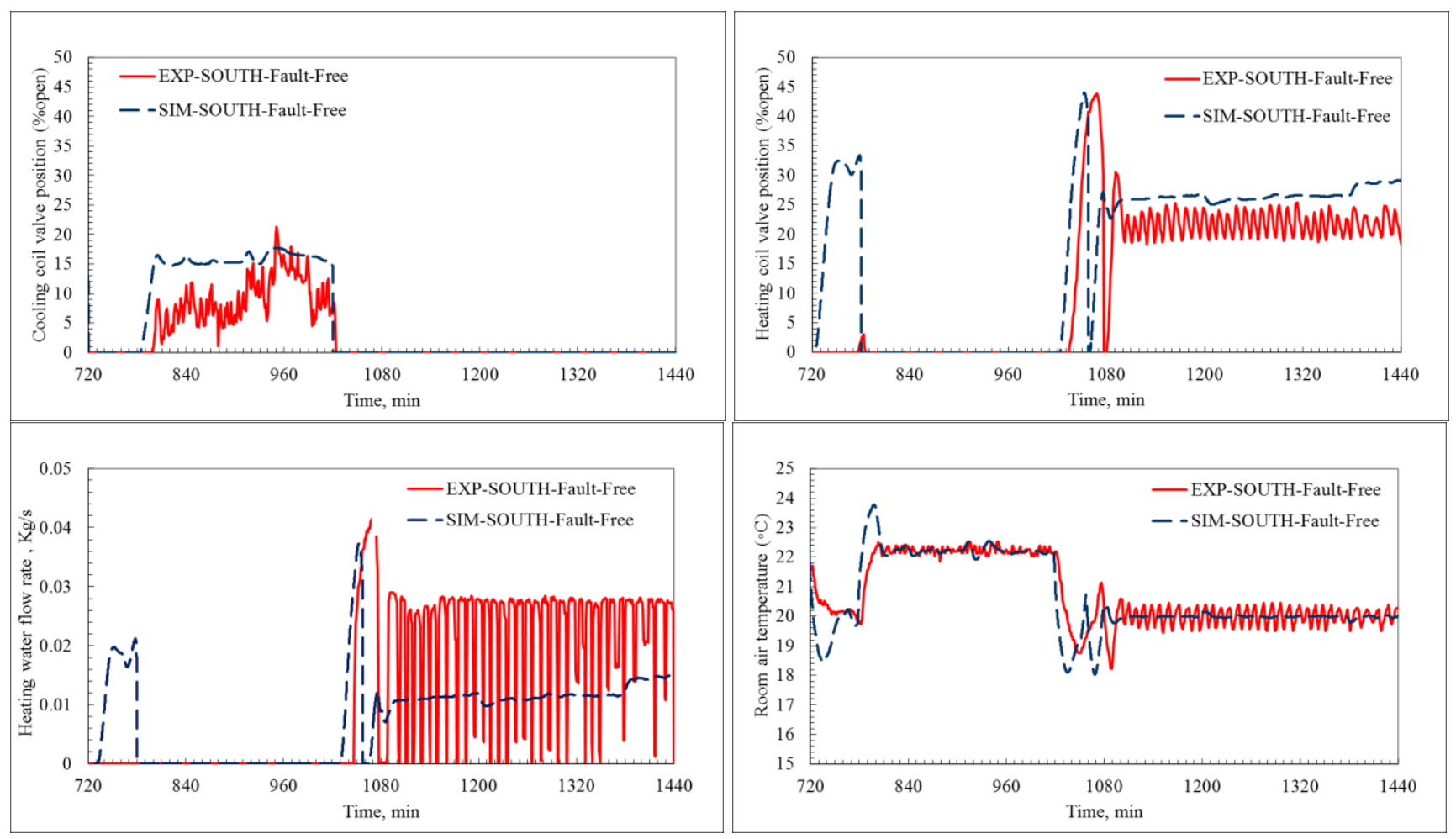

(b) South-facing room validation results

Figure $7 \quad$ FCU fault-exclusive simulation result comparison with the real operational data

Another large difference is the oscillation of the heating and cooling coil valve and the resulting oscillation of room air temperature. The control system responds to the feedback from the room temperature sensor, so any fluctuation in the sensor reading is unavoidably transferred to the control system and vice versa. The actual room temperature sensor fluctuations result in the fluctuations of cooling and heating coil valve position in the experimental data and consequently heating water flow rate. In the experimental data, the oscillation of heating/cooling coil valves and also the head pressure of the hot/chilled water loops amplify the fluctuation of heating/cooling water flow rate through the valve.

To illustrate fault-inclusive model validation, an example including a control fault, sensor fault, and equipment fault is discussed. The misdirected heating control fault is illustrated with an example from the east-facing zone on a winter evening (01.14.2012). A misdirected actuator is a typical commissioning fault usually caused by incorrect setting of the directional switch on the actuator. During this fault, the actuator answers the control signal command by moving the wrong way (i.e., the actuator closes down the heating valve instead of opening it). A warmer normal test day would cause the system variables to behave similarly to the fault, so such a day is chosen as a reference day. For example, on a warm day the heating coil valve position in the fault-free case will be lower, which is the same behavior that occurs on a cold day with a misdirected heating control fault. Figure 8 shows the comparison of outdoor air temperature of the available normal test days and the given faulty test day. In this figure, the normal test day outdoor air temperatures are shown by solid lines and the dotted line is the temperature on the faulty test day (Jan $14^{\text {th }}$ ). As this figure shows, Jan $8^{\text {th }}$ is warmer than Jan $14^{\text {th }}$ and is therefore selected as the reference day. Figure 9 is a comparison of simulation results under faulty and fault-free conditions with the corresponding experimental data. Red and dashed navy blue lines represent experimental data and simulation results, respectively, under the faulty condition. Purple and green lines represent experimental data and simulation results under the fault-free condition. The symptoms of the heating coil misdirection fault can be readily distinguished by noticing:

1) The contradiction of heating coil valve position and heating water flow rate. The controller is sending a signal 
for the heating coil valve to be closed, but the heating water flow rate is at the maximum level.

2) The heating coil valve position on a cold winter evening (below $-1.11^{\circ} \mathrm{C}$ or $30^{\circ} \mathrm{F}$ ). According to the faultfree experimental data, the east-facing room on a warmer normal day calls for heating, but under the fault condition the valve is $0 \%$ open. The same behavior is displayed in the simulation result for a fault-free condition.

3) The cooling coil valve position on a cold winter evening (below $-1.11{ }^{\circ} \mathrm{C}$ or $30{ }^{\circ} \mathrm{F}$ ). Under the faulty condition on a winter evening, the zone calls for cooling in both the experiment and simulation cases due to the extremely hot supply air, which is caused by excess hot water flow rate through the heating coil.

4) The room temperature maintained at cooling setpoint. For the fault condition, the FCU is operating in cooling mode, so room temperature is kept near the cooling setpoint, while for the fault-free condition it is fluctuating around the heating setpoint.

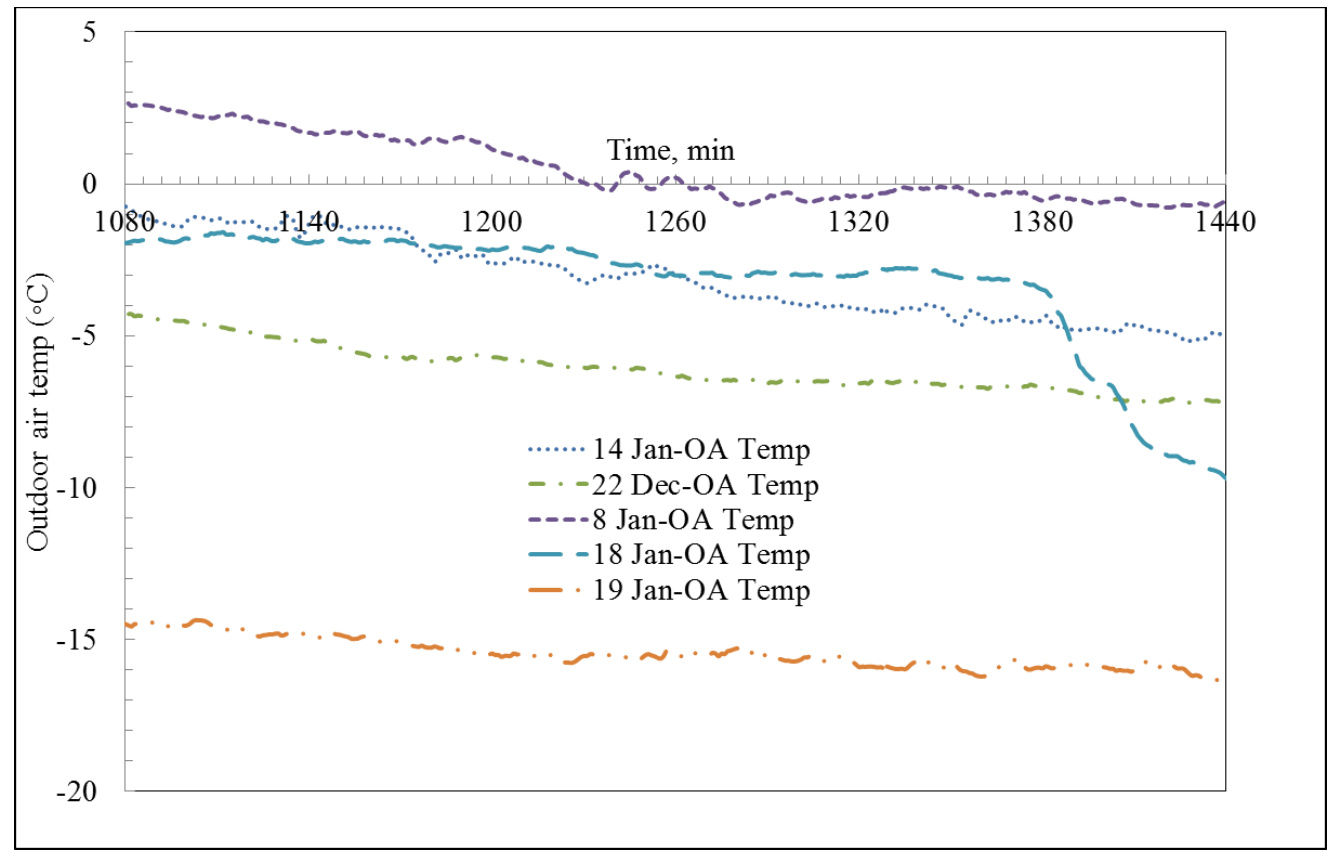

Figure 8 Outdoor air comparison of Jan $14^{\text {th }}$ with the other normal test days in order to select a reference day
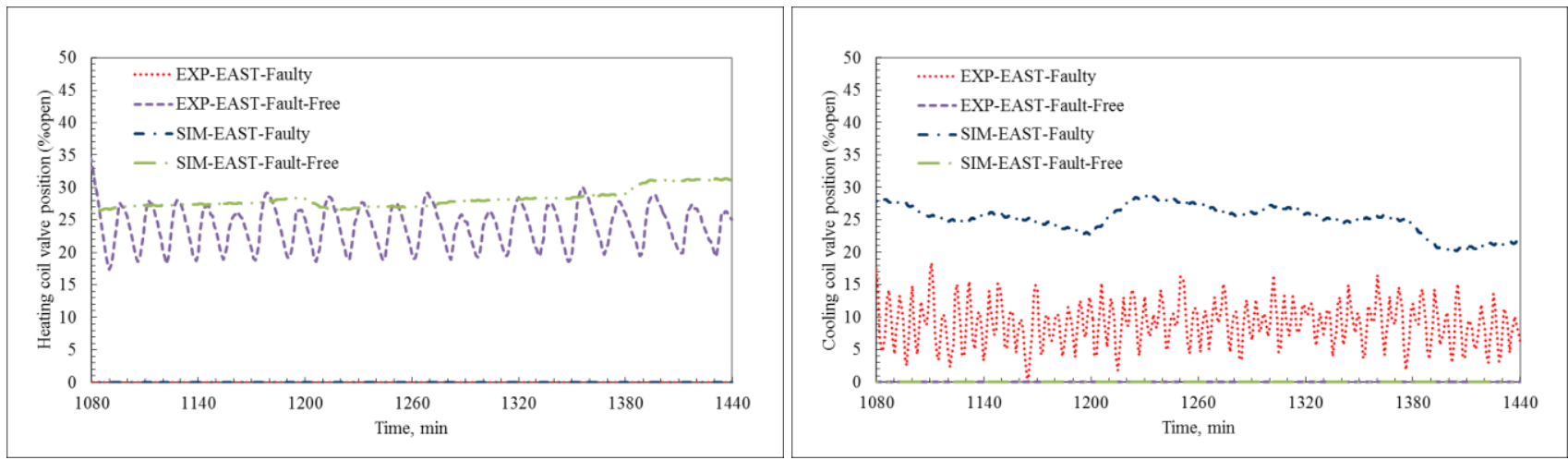

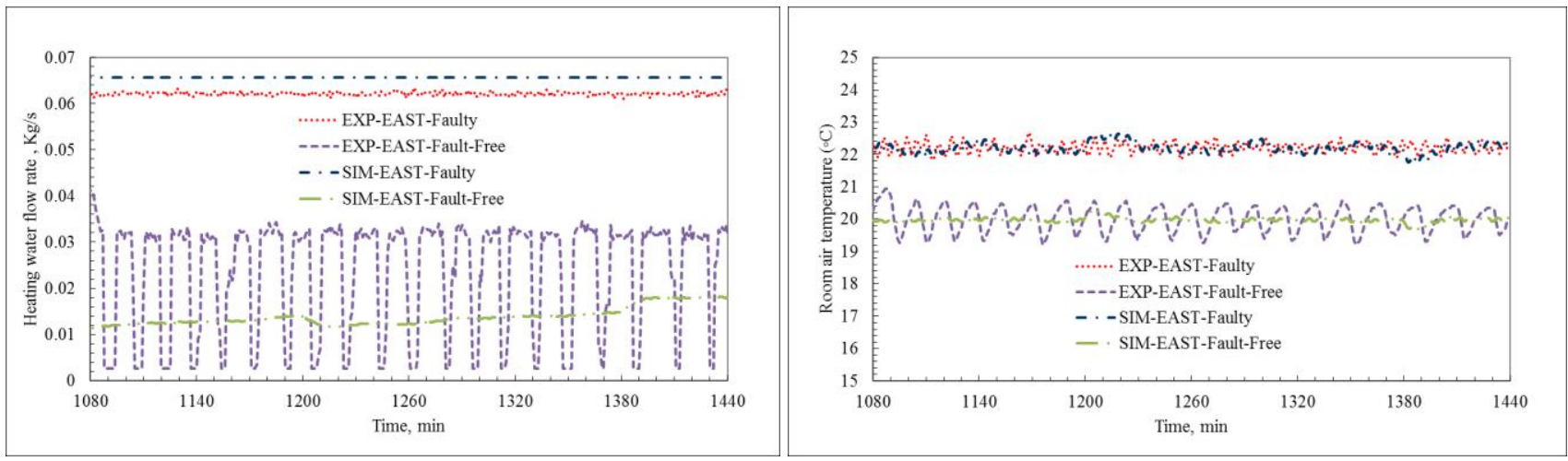

Figure 9 FCU fault-exclusive and fault-inclusive simulation results comparison with the real operational data (misdirected heating control fault)

The next fault addressed is a spurious offset in measurements by a room temperature sensor. In this example, a +1.11 ${ }^{\circ} \mathrm{C}\left(+2{ }^{\circ} \mathrm{F}\right)$ room temperature offset fault is demonstrated in the west-facing room on a winter test day (01.04.2012). The closest normal test day was selected to serve as a reference day $\left(\operatorname{Jan} 8^{\text {th }}\right)$. As Figure 10 depicts, the symptoms associated with this fault are the following:

1) Decrease in heating coil valve position and hot water flow rate. The room temperature sensor reading is passed to the controller in order to maintain room temperature by adjusting the heating and cooling coil valve positions. The room temperature sensor offset causes an artificial decrease in the room heating load and heating coil load decreases accordingly.

2) Decrease in the room temperature by $+1.11^{\circ} \mathrm{C}\left(+2{ }^{\circ} \mathrm{F}\right)$. The dashed navy blue line represents the sensor reading (output of sensor superblock) while the light blue line represents the room temperature (output of thermal superblock) under the faulty condition. The simulated room temperature under the faulty condition is $+1.11{ }^{\circ} \mathrm{C}$ $\left(+2{ }^{\circ} \mathrm{F}\right)$ less than the temperature sensor reading.

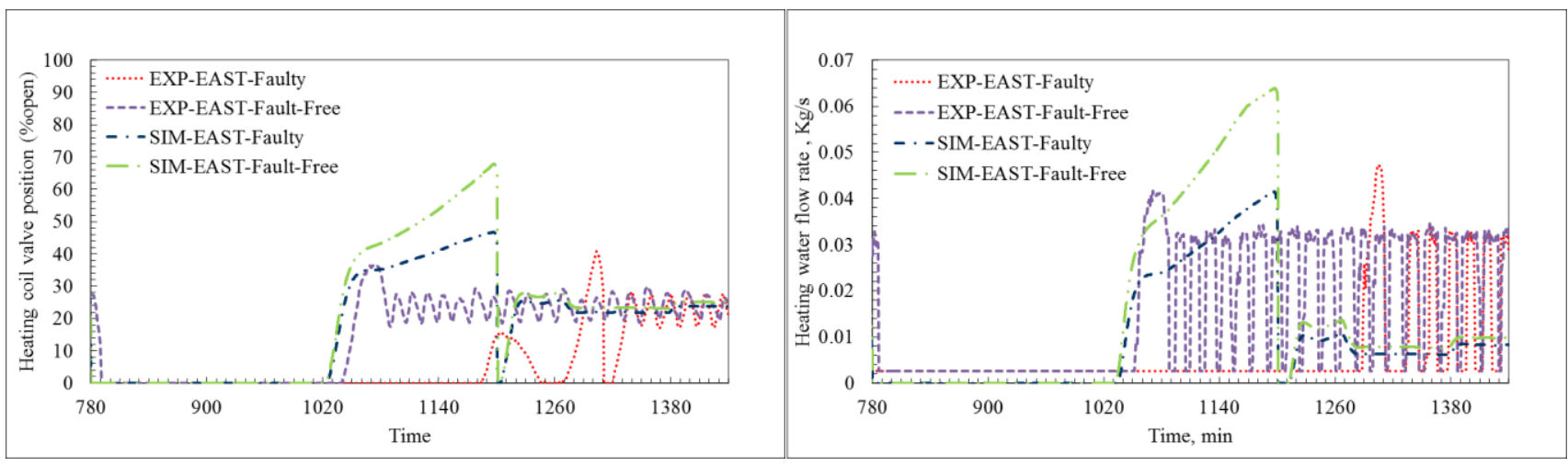




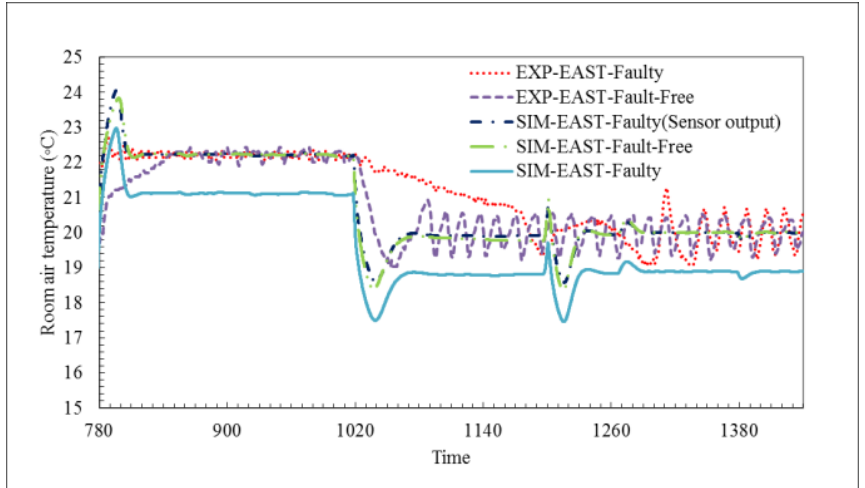

Figure 10 FCU fault-exclusive and fault-inclusive simulation results comparison with the real operational data (room temperature sensor bias fault $\left(+1.11^{\circ} \mathrm{C}\right.$ or $\left.+2{ }^{\circ} \mathrm{F}\right)$

Finally, the fault of having fouling on cooling coil water side surfaces is discussed. This fault was applied to the west facing room on a summer test day (07.24.2011). Water side fouling occurs when minerals in the circulating water deposit on the surfaces of the heat exchanger in contact with the water. This phenomenon results in heat exchanger performance degradation by reducing the overall heat transfer coefficient and increasing the resistance to fluid flow. In the experiment, the water side fouling fault test was created by restricting the maximum water flow rate through the coil to mimic the increase of resistance to water flow. Thus, the heat transfer coefficient of the coil did not change during the experiment. This fault was created in the model by increasing water side pressure resistance without manipulating the heat transfer coefficient of the cooling coil. The closest normal test day to serve as a reference day was July $16^{\text {th }}$. As Figure 11 shows the symptoms associated with this fault are:

1) Increase in the cooling coil valve position. Cooling water flow is restricted due to this fault, and this reduction in flow during cooling mode operation of the FCU is compensated for by an increase in the valve position.

2) Increase in room air temperature. An increase in the cooling coil valve position in the morning results in sufficient chilled water flow and room temperature is maintained at set point. The consequences of restricted chilled water flow show up in an obvious effect in the afternoon. Even when the cooling coil valve is fully open, the water flow rate is inadequate and the room temperature cannot be maintained at set point.
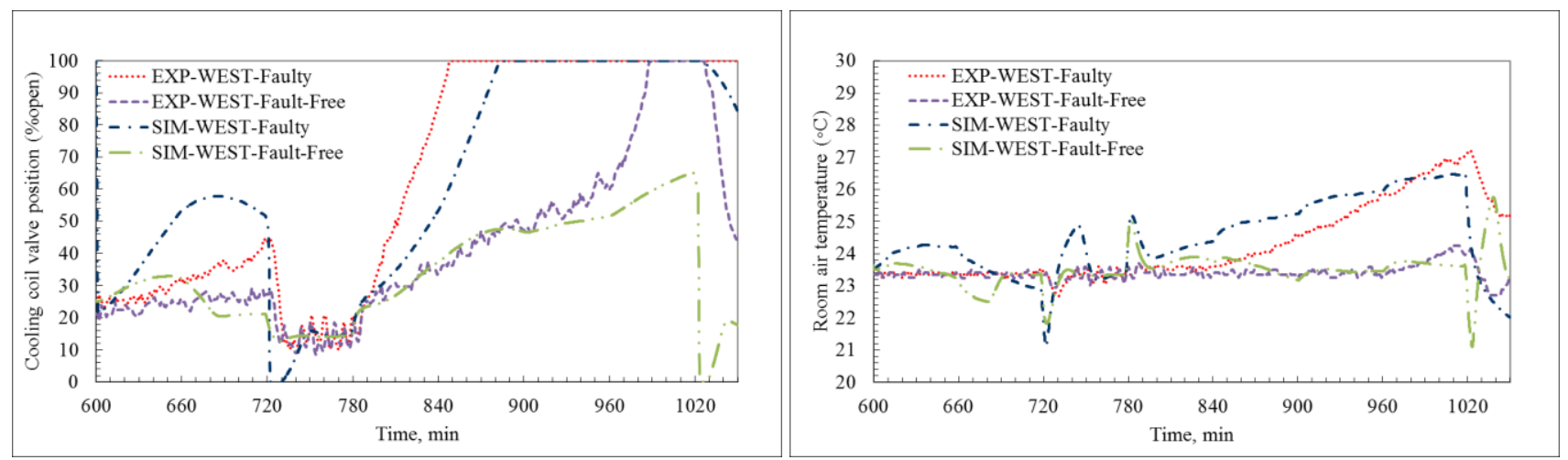

Figure 11 FCU fault-exclusive and fault-inclusive simulation results comparison with the real operational data (cooling coil water side fouling fault)

As illustrated by these three fault-inclusive model validation cases, the developed fault-inclusive FCU model successfully reproduces all fault symptoms observed from experimental data, although the exact dynamics may not be the 
same as the experimental data.

\section{SUMMARY}

A validated, dynamic numerical model of a FCU has been developed as a single integrated component for inclusion in the component library of the HVACSIM+ simulation package by adding three new TYPEs to that library. The structure of the FCU model and the justification for using the HVACSIM+ package in particular have been discussed. Validation of the FCU model started with component level validation, followed by system level validation in which the model was "installed" within an overall system. Experiments were conducted to investigate and determine key model parameters to specifically represent the FCU at the test facility. Real operational data provided by ERS served as a reference to which simulation results were compared. For validation of the model, simulation results including control signals such as cooling and heating coil valve positions along with hot water flow rate and room air temperature are compared against experimental data. Under fault-free conditions, the FCU model agreed well with reference data for several days in different seasons (summer, fall and winter). A fault flag system gives the model the flexibility to simulate various faults modes with differing severities without the need to develop additional TYPEs. The model was tested on a fault matrix and validated against experimental data. The purpose of validating the fault-inclusive model is to replicate fault symptoms rather than regenerating the dynamics of the system one by one. The fault-inclusive model was validated for the potential fault matrix included in the paper and various weather conditions (transient season, winter and summer), establishing its validity to serve as a tool for evaluating FCU fault detection and diagnostic methods.

\section{ACKNOWLEDGEMENT}

Financial support provided by the National Institute of Standard Technology (Grant NIST 10D243) is greatly appreciated.

\section{REFERENCES}

ASHRAE. 2008. ASHRAE Handbook-Systems \& Equipment, Chapter 12. Atlanta: American Society of Heating Refrigeration and Air Conditioning Engineers, Inc.

Bendapudi, S., and J. E. Braun, 2002. Development and Validation of a Mechanistic, Dynamic Model for a Vapor Compression Centrifugal Liquid Chiller, Report \#4036-4, Deliverable for Research Project 1043-RP, ASHRAE, Atlanta, GA.

Bushby, S. T., Castro, N., Galler, M. A., and C. Park. 2001. Using the virtual cybernetic building testbed and AFDD test shell for AFDD tool development. NISTIR 6818, National Institute of Standards and Technology, Gaithersburg, MD.

Castro, N. S., Schein, J., Park, C., Galler, M. A., Bushby, S. T., and J. M. House. 2003. Results from simulation and laboratory testing of air handling unit and variable air volume box diagnostic tools, NISTIR 6964, National Institute of Standards and Technology, Washington, DC.

Chu, C. M., Jong, T. L., and Y. W. Huang. 2005. Thermal comfort control on multi-room fan coil unit system using LEEbased fuzzy logic. Energy Conversion \& Management, 46: 1579-1593.

Colmenar-Santos, A., de Lober, L.N.T., Borge-Diez, D. and Castro-Gil, M., 2013. Solutions to reduce energy consumption in the management of large buildings. Energy and Buildings, 56, pp.66-77.

Comstock, M. C. and J. E. Braun. 1999a. "Experimental Data from Fault Detection and Diagnostic Studies on a Centrifugal Chiller," Ray W. Herrick Laboratories, HL 99-18: Purdue University, West Lafayette, IN.

Comstock, M. C. and J. E. Braun. 1999b. "Development of Analysis Tools for the Evaluation of Fault Detection and Diagnostics in Chillers," Ray W. Herrick Laboratories, HL 99-20: Purdue University, West Lafayette, IN.

DeSimone, M. 1996. A standard simulation testbed for the evaluation of control algorithms and strategies related to variable air volume HVAC system. Massachusetts Institute of Technology, Cambridge, MA, M.S. Thesis.

Dexter, A. L., Eftekhari, M. M., Haves, P., and J. G. Jota. 1987. The use of dynamic simulation models to evaluate algorithms for building energy control: Experience with HVASIM+. Proceedings of ICBEM'87, International Congress on Building Energy Management, October, Lausanne, Switzerland.

Dexter, A. L. 1995. Fuzzy model based fault diagnosis. IEE Proceedings - Control Theory Application, 142 (6): 545- 550. 
Ghiaus, C. 2001. Fuzzy model and control of a fan-coil. Energy and Building, 33: 545-551.

Haves, P. 1997. Fault modeling in component-based HVAC simulation. Proceedings of Building Simulation 97, IBPSA: 119- 126.

Katipamula, S. R. G. Pratt, and J. Braun, 2001. "Building System Diagnostics and Preventive Maintenance," Section 7.2, Handbook of Heating, Ventilation, and Air Conditioning, CRC Press, Boca Raton, FL.

Katipamula, S. and M.R. Brambley, 2005a,b. Methods for fault detection, diagnostics, and prognostics for building systems, Part I and II. HVAC\&R Research Journal, Jan, April.

Ke, M., Weng, K. and C. Chiang. 2007. Performance evaluation of an innovative fan-coil unit: Low-temperature differential variable air volume FCU. Energy and Building, 39(6): 702-708.

Kwak, Y., Huh, J.H. and Jang, C., 2015. Development of a model predictive control framework through real-time building energy management system data. Applied Energy, 155, pp.1-13.

Li, S., and J. Wen. 2010. Development and validation of a dynamic air handling unit model (Part I, RP 1312). ASHRAE Transactions, 116(1): 45-56.

Li, S., Wen, J., Zhou, X., and C. J. Klaassen. 2010. Development and validation of a dynamic air handling unit model (Part II, RP 1312). ASHRAE Transactions, 116(1): 57-73.

Li, P., Qiao, H., Li, Y., Seem, J.E., Winkler, J. and Li, X., 2014. Recent advances in dynamic modeling of HVAC equipment. Part 1: Equipment modeling. HVAC\&R Research, 20(1), pp.136-149.

Norford, L. K. and P. Haves. 1997. A Standard Simulation Testbed for the Evaluation of Control Algorithms and Strategies. Final Report of ASRAE 825-RP. American Society of Heating, Refrigerating, and Air-Conditioning Engineers, Inc.: Atlanta, Georgia.

Norford, L. K., Wright, J. A., Buswell, R. A., and D. Luo. 2000. Demonstration of fault detection and diagnosis methods in a real building. Final Report of ASHRAE 1020RP. Atlanta: American Society of Heating, Refrigerating, and AirConditioning Engineers, Inc.

Pang, X., Wetter, M., Bhattacharya, P. and Haves, P., 2012. A framework for simulation-based real-time whole building performance assessment. Building and Environment, 54, pp.100-108.

Park, C., Clark, D. R., and G. E. Kelly. 1985. An overview of HVACSIM+, a dynamic building/ HVAC/ control system simulation program. The 1st Annual Building Energy Simulation Conference, Seattle, WA, August 21-22.

Peitsman, H. C., and L.L. Soethout. 1997. ARX models and real-time model-based diagnosis. ASHRAE Transactions, 103 (1): 657-671.

Price, B. A., and T. F. Smith. 2003. Development and validation of optimal strategies for building HVAC systems. Technical Report: ME-TEF-03-001, Department of Mechanical Engineering, The University of Iowa, Iowa City, Iowa.

Privara, S., Cigler, J., Váňa, Z., Oldewurtel, F., Sagerschnig, C. and Žáčeková, E., 2013. Building modeling as a crucial part for building predictive control. Energy and Buildings, 56, pp.8-22.

Schein, J. and S. Bushby, "A Simulation Study of a Hierarchical, Rule-Based Method for System-Level Fault Detection and Diagnostics in HVAC Systems”, Technical Report, NISTIR 7216, U.S DEPARTMENT OF COMMERCE, National Institute of Standard and Technology, Building Environment Division, Building and Fire Research Laboratory, Gaithersburg, MD 20899-8631, 2005.

Schein, J. "Results from Field Testing of Embedded Air Handling Unit and Variable Air Volume Box Fault Detection Tools", Technical Report, NISTIR 7365, U.S DEPARTMENT OF COMMERCE, National Institute of Standard and Technology, Building Environment Division, Building and Fire Research Laboratory, Gaithersburg, MD 20899-8631, 2006.

Wen, J. and Li, S., 2011. Tools for Evaluating Fault Detection and Diagnostic Methods for Air-Handling Units, ASHRAE Research Project 1312 Final Report, ASHRAE, Atlanta, GA.

Yu, Y., Woradechjumroena, D. and D. Yu. 2014. A review of fault detection and diagnosis methodologies on air-handling units. Energy and Buildings, 82: 550-562. 